Absolute Configuration of Alkaloids from Uncaria longiflora through Experimental and Computational Approaches

Author(s): Fatimah Salim, Yusri Mohd Yunus, El Hassane Anouar, Khalijah Awang, Moses

Langat, Geoffrey A. Cordell, and Rohaya Ahmad

Supporting Information 


\section{Table of Content}

Content

Page

Figure 1. ${ }^{1} \mathrm{H}$ NMR spectra of alkaloids $\mathbf{1}$ (a), 2 (b) and $\mathbf{3}$ (c).

Table 1. Conformer analysis of alkaloid $\mathbf{1 .}$

Table 2. Conformer analysis of alkaloid 2.

Table 3. Conformer analysis of alkaloid $\mathbf{3}$.

Figure 2. Experimental and calculated UV/Vis spectrum of alkaloid 1.

Figure 3. Experimental and calculated UV/V is spectrum of alkaloid 2.

Figure 4. Experimental and calculated UV/V is spectrum of alkaloid 3. 
(a)

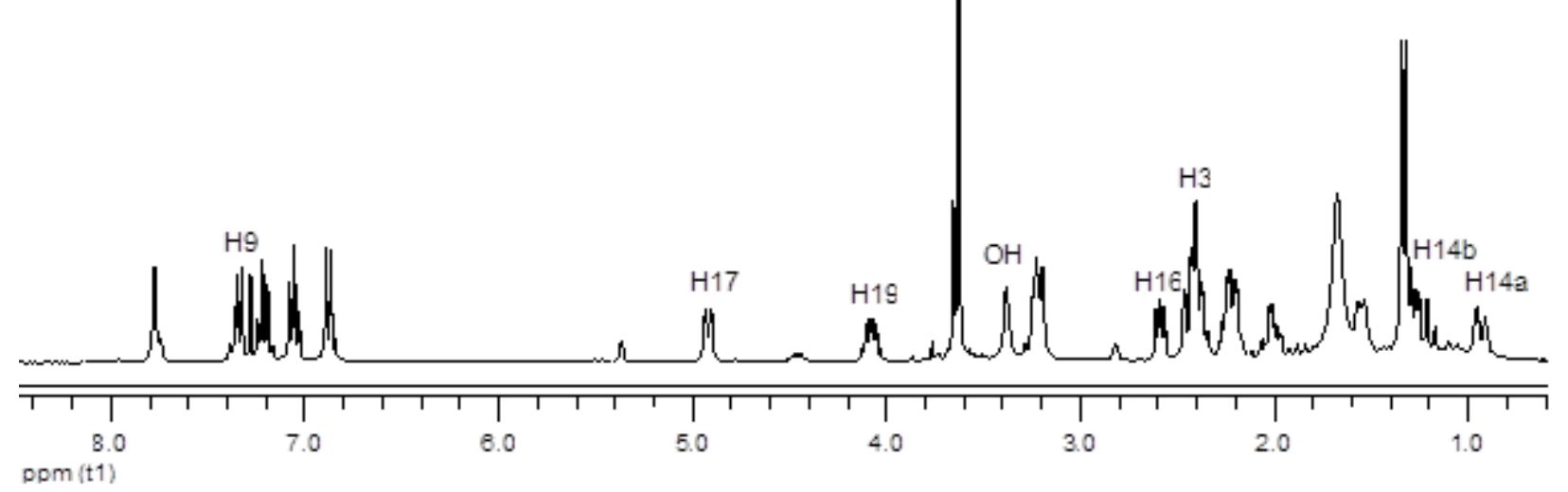

(b)

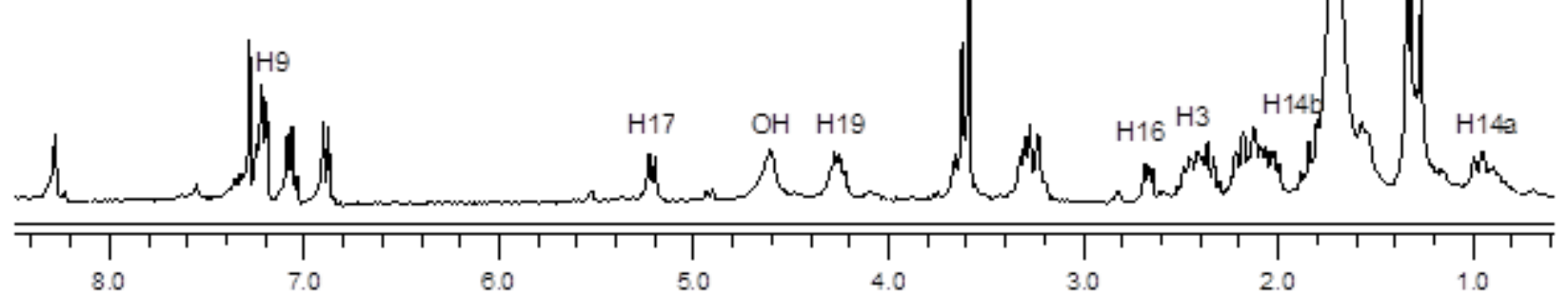
$\mathrm{ppm}(\mathrm{t} 1)$

(c)
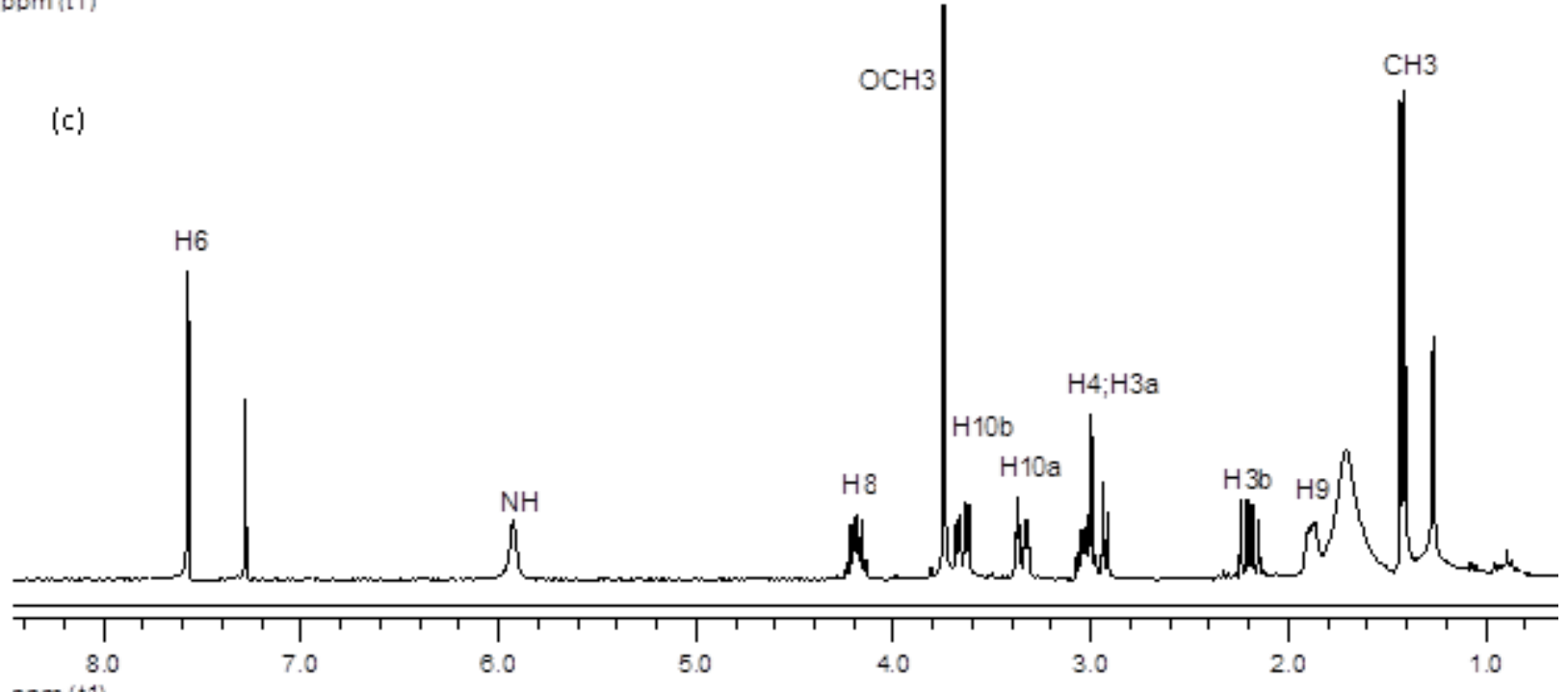
$\operatorname{ppm}(\mathrm{t} 1)$

Figure 1. ${ }^{1} \mathrm{H}$ NMR spectra of alkaloids 1 (a), 2 (b) and 3 (c): (a) and (b) showing the effect of spiro $\mathrm{C}-7$ configuration on chemical shifts of $\mathrm{H}-9, \mathrm{H}-3$, and $\mathrm{H}-14 \beta$ where the former possesses $7 S$, and the latter possesses $7 R$. All the spectra were acquired in $\mathrm{CDCl}_{3}$. 
Table 1

Conformer analysis of alkaloid $\mathbf{1}$.

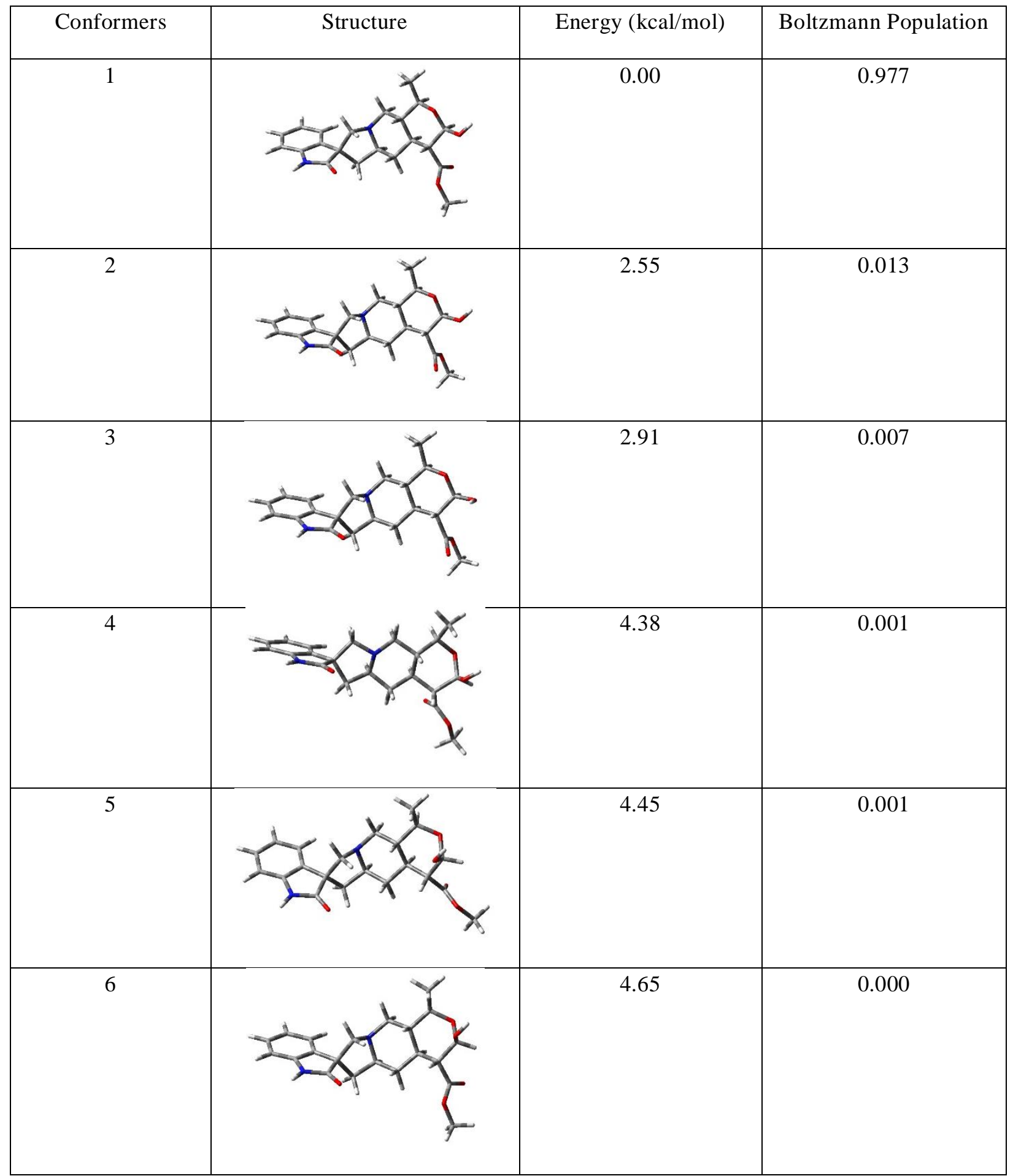




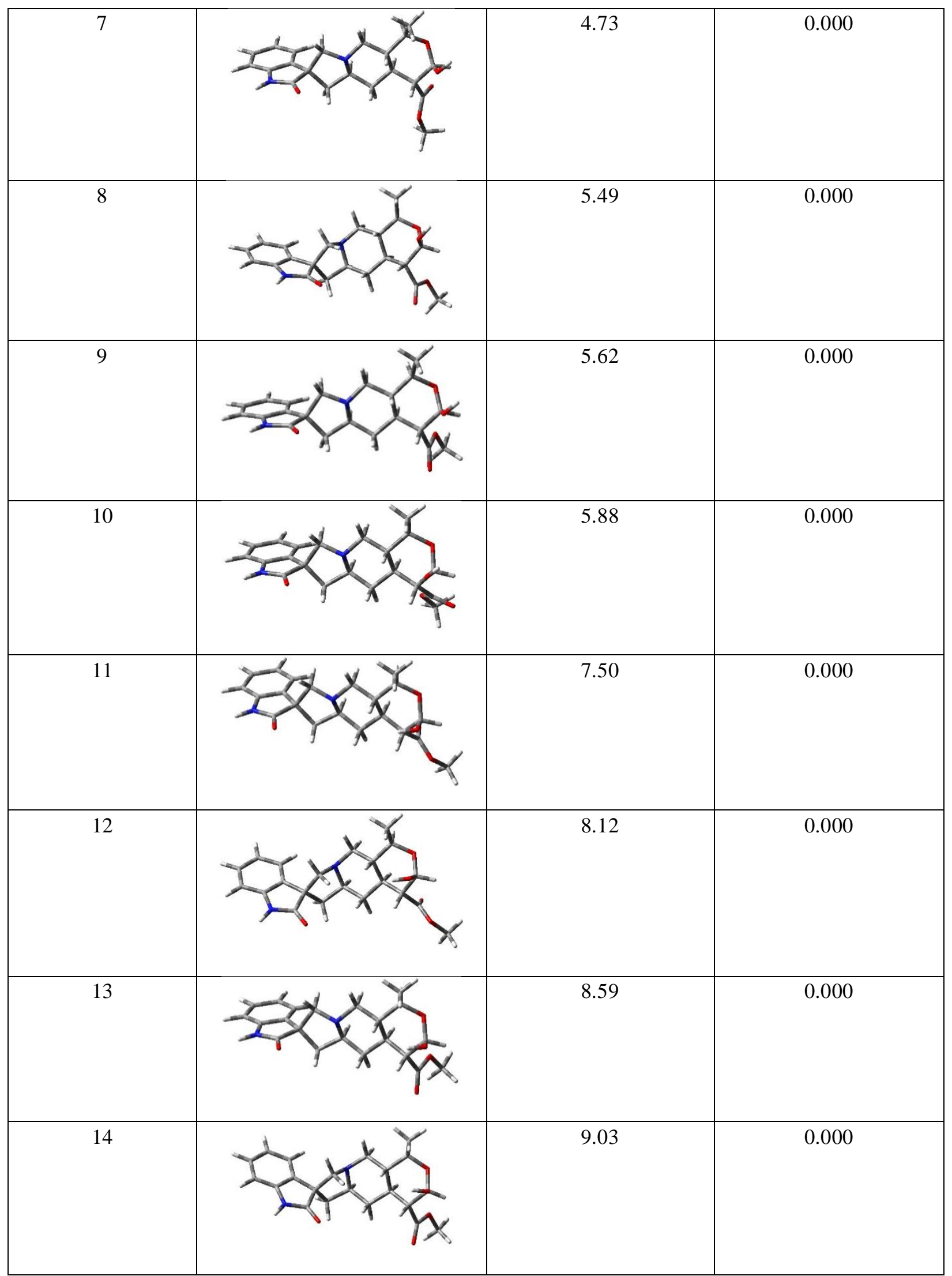


Table 2

Conformer analysis of alkaloid $\mathbf{2}$.

\begin{tabular}{|c|c|c|c|}
\hline Conformers & Structure & Energy $(\mathrm{kcal} / \mathrm{mol})$ & Boltzmann Population \\
\hline 1 & & 0.00 & 0.400 \\
\hline 2 & & 0.05 & 0.371 \\
\hline 3 & & 0.63 & 0.139 \\
\hline 4 & & 0.98 & 0.077 \\
\hline 5 & & 2.13 & 0.011 \\
\hline 6 & & 3.62 & 0.001 \\
\hline
\end{tabular}




(1)


Table 3

Conformer analysis of alkaloid $\mathbf{3}$.

\begin{tabular}{|c|c|c|c|}
\hline Conformers & Structure & Energy $(\mathrm{kcal} / \mathrm{mol})$ & Boltzmann Population \\
\hline 1 & & 0.00 & 0.481 \\
\hline 2 & & 0.39 & 0.251 \\
\hline 3 & & 0.86 & 0.112 \\
\hline 4 & & 1.29 & 0.054 \\
\hline 5 & & 1.35 & 0.050 \\
\hline
\end{tabular}




\begin{tabular}{|c|c|c|}
\hline 6 & 1.35 & 0.049 \\
\hline 7 & 3.50 & 0.001 \\
\hline 8 & 3.50 & 0.001 \\
\hline
\end{tabular}




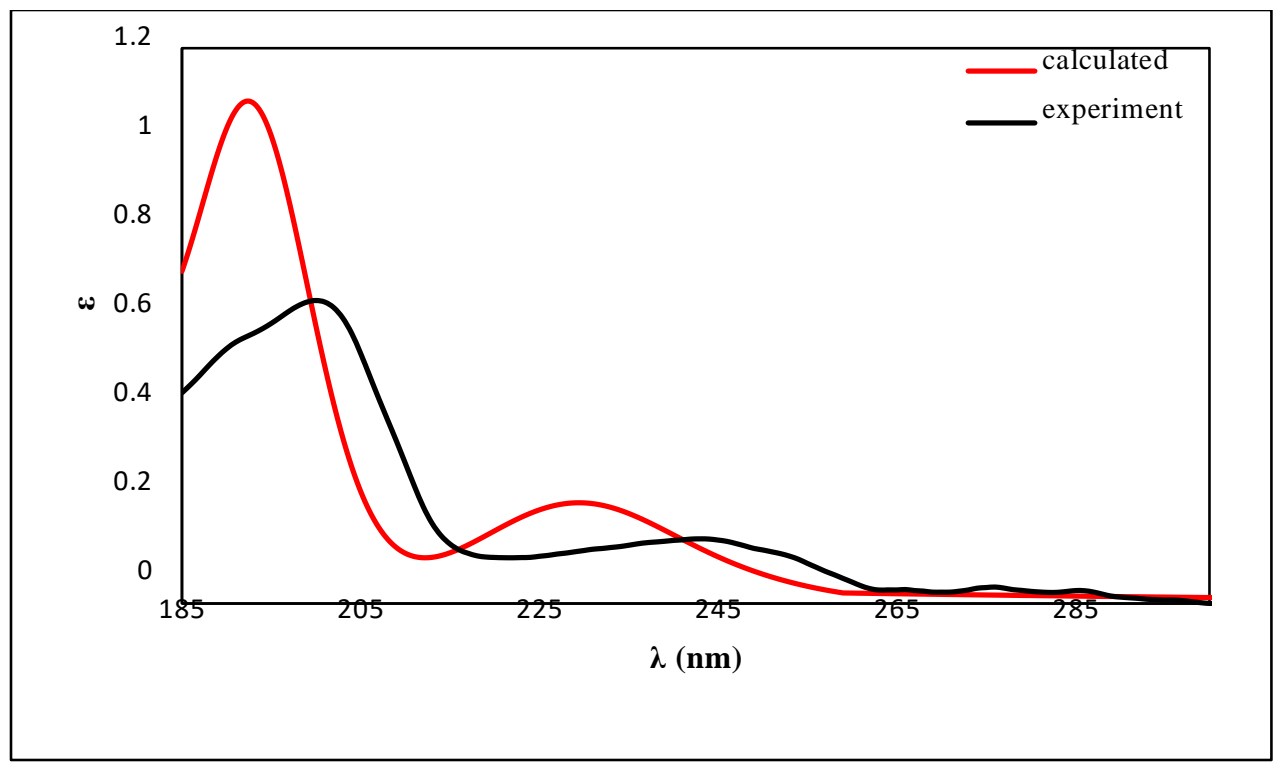

Figure 2. Experimental and calculated UV/Vis spectrum of Alkaloid 1

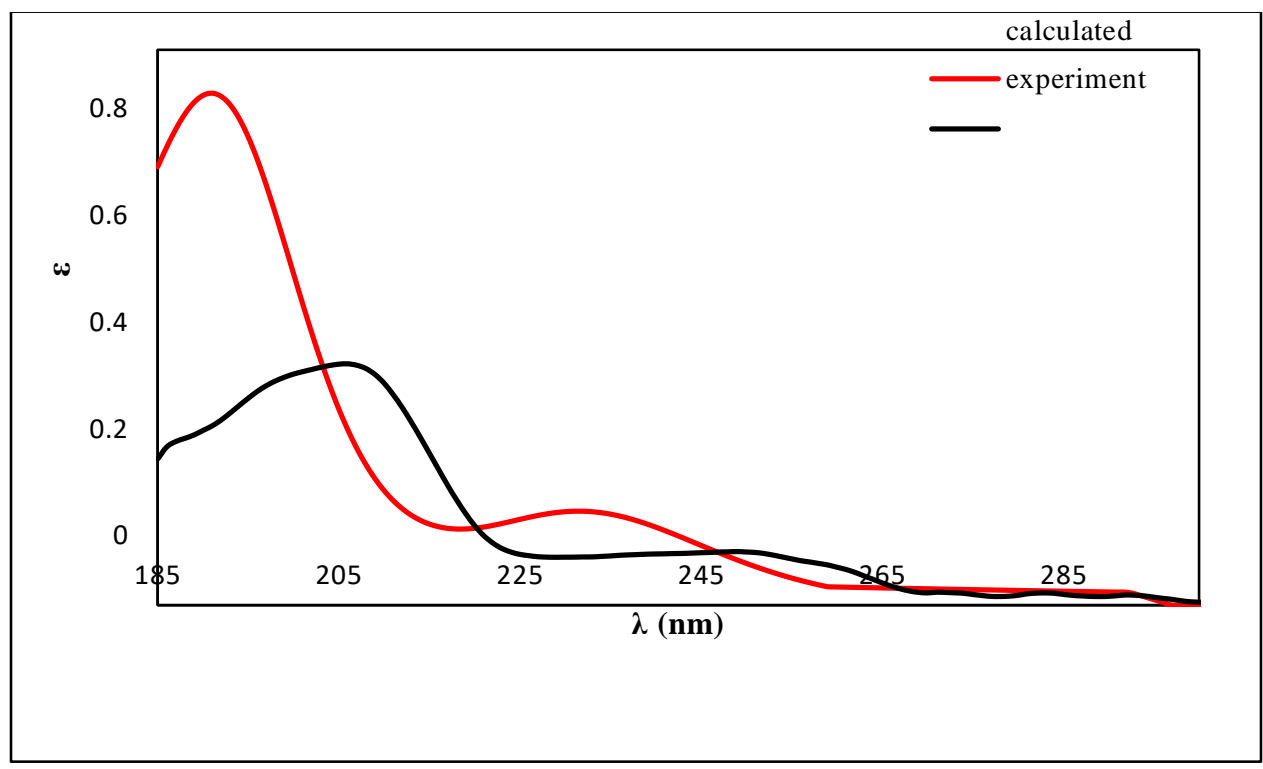

Figure 3. Experimental and calculated UV/Vis spectrum of Alkaloid 2. 


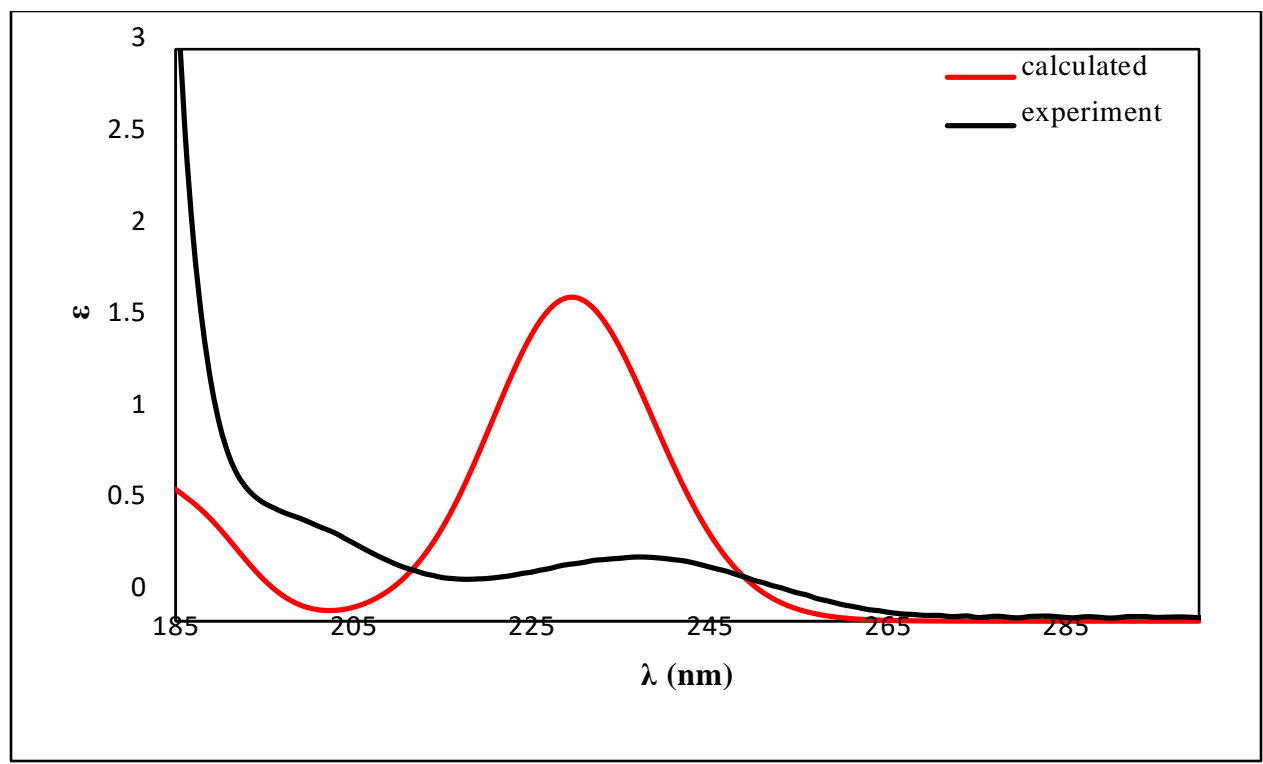

Figure 4. Experimental and calculated UV/Vis spectrum of Alkaloid 3. 